\title{
Entre a "Empfindsamkeit" e o Romantismo: a estética musical segundo Wackenroder e Tieck
}

\author{
Mário Videira* \\ (Universidade de São Paulo/ECA)
}

\section{Resumo}

O principal objetivo deste artigo é investigar o problema referente à autonomia estética da música, por meio do exame de textos literários e filosóficos. Com sua "revolução filosófica", Kant acentuou a subjetividade de maneira radical, abrindo, pela primeira vez, a possibilidade da música ser reconhecida como uma forma de acesso ao Absoluto, que foi posteriormente desenvolvida por autores como Wackenroder e Tieck.

Palavras-chave: aesthetic autonomy; instrumental music; German Romanticism, Wackenroder; Tieck.

\footnotetext{
* Mário Videira, pianista, graduado em Música e Filosofia pela Universidade de São Paulo, possui mestrado em Musicologia (Unesp) e doutorado em Filosofia (USP). Atualmente, é professor e pesquisador do Departamento de Música da Escola de Comunicações e Artes da USP. É autor de O Romantismo e o Belo Musical (Ed. Unesp, 2006) e tradutor de Berg: o mestre da transição mínima, de T. W. Adorno (Ed. Unesp, 2010). Publicou também diversos artigos sobre Estética e Filosofia da Música em revistas especializadas, tanto no Brasil como no exterior.
} 


\section{Introdução}

O "primeiro manifesto" do Romantismo alemão, na opinião de alguns comentadores, ${ }^{1}$ encontra-se num livro relativamente curto, publicado anonimamente em Berlim no final de 1796. Seu título: Herzensergießungen eines kunstliebenden Klosterbruders [Efusões do coração de um monge amante da arte]. Escrito por Wackenroder e Tieck, o livro consiste numa série de ensaios, principalmente sobre a pintura e a música, a relação entre arte e religião, o problema do gênio e o tema da inadequação do artista ao mundo prosaico. Em 1799, cerca de um ano após a morte prematura de Wackenroder, Tieck editou uma espécie de continuação desse livro, desta vez com um número maior de textos de sua autoria, ao qual deu o título de Phantasien über die Kunst [Fantasias sobre a arte]. Também aqui, encontramos novamente a figura do mongenarrador e os mesmos temas presentes no livro anterior. É bastante provável que o tom de devoção religiosa adotado pelo narrador tenha contribuído para o surgimento das interpretações que consideram os textos de Wackenroder como produtos de um diletante ingênuo e sem maiores ambições teóricas. Nada mais longe da realidade: ambos os livros contêm reflexões teóricas importantes e, de fato, não é exagero considerá-los como o primeiro manifesto do movimento romântico, pois, embora não se possa afirmar que esses textos tenham surgido como uma resposta direta às questões colocadas pela filosofia de Kant ${ }^{2}$ e Fichte

\footnotetext{
${ }^{1}$ Cf., por exemplo, F. Strack (1978, p. 369-391) e também R. Alewyn (1944, p. 48-58).

2 Pode-se supor, contudo, que Wackenroder e Tieck tivessem contato com a filosofia de Kant por intermédio de Reichardt. Que a filosofia de Kant não Ihes era inteiramente alheia, é o que se pode depreender também de um relato de Tieck acerca de uma viagem a Jena. Numa carta à sua irmã, datada de 02 de maio de 1793, Tieck menciona uma discussão sobre a filosofia de Kant e se refere a Reinhold em termos bastante elogiosos: "Fomos de Drakendorf a Jena a pé, a fim de visitar diversas pessoas. Reinhold (penso que tu és ignorante o suficiente para não o conhecer: ele é o primeiro dentre os kantianos, um homem a quem venero quase tanto quanto Schiller) foi nossa primeira visita. Ele é um homem excelente e, sem querer ser pretencioso, logo ficamos bons amigos [...]. Gostaria de vir estudar em Jena, para pode ouvir suas aulas" (Wackenroder, HKA II, p. 248). No entanto, como não há nenhuma referência direta à filosofia de Kant, seja nos Herzensergießungen, seja nas Phantasien, optamos por situá-los antes do capítulo dedicado à recepção da filosofia kantiana, assumindo a mesma perspectiva adotada por Dirk Kemper, que se concentra mais na ruptura e superação de outros filósofos do século XVIII, como Sulzer e Ramler.
} 
(tal como ocorreu no chamado "Círculo de Jena"), sua influência pode ser verificada em textos de August e Friedrich Schlegel, ${ }^{3}$ Schleiermacher, Schelling e Hoffmann, entre outros. A amplitude dos interesses teóricos de Wackenroder e Tieck está documentada em suas cartas dos anos de 1792 e 1793 . Em diversas passagens há menções a Longino, Shakespeare, Ossian, Hamann, Reinhold, Goethe, Lessing, Schiller, Diderot, Heinse, Winckelmann, Lairesse, Dubos e Sulzer. Além disso, os dois eram frequentadores assíduos da residência do compositor J. F. Reichardt, ${ }^{4}$ assistiram aos cursos de estética e história da arte dados por K. P. Moritz (Cf. Hubert, 1971, p. 26) na Academia de Belas-Artes de Berlim, e foram alunos de Forkel (História da Música) na Universidade de Göttingen (Behler, 1996, p. 25). A influência desses autores pode ser percebida no tratamento de diversos temas abordados nos textos de Wackenroder e Tieck.

\section{Desabafos e fantasias de um monge amante da arte}

Os textos de Wackenroder e Tieck são presença constante nos livros que abordam a estética musical do Primeiro Romantismo. No entanto, uma questão

52 que pode ser levantada com relação a muitos desses estudos diz respeito ao fato de não se levar em consideração que, tanto os Herzensergießungen quanto as Phantasien fazem parte de um conjunto ficcional. Embora o excelente livro editado no final dos anos 60 por Elmar Hertrich ${ }^{5}$ - o qual, no entanto, aborda somente o personagem Joseph Berglinger - constitua uma exceção, pode-se dizer que a grande maioria dos historiadores se contentou apenas em citar uma ou

\footnotetext{
${ }^{3}$ De acordo com Ernst Behler, a influência de Wackenroder sobre o círculo dos Primeiros Românticos de Jena manifestou-se, sobretudo no interesse pela pintura, "no diálogo Os Quadros de August e Caroline Schlegel, nas descrições de pinturas realizadas por Friedrich Schlegel em Europa, e no lugar de destaque que a pintura alcançou na teoria da arte do Romantismo tardio." (Behler, 1996, p. 27)

${ }^{4}$ Há testemunhos, inclusive, de que Wackenroder teria tido aulas de composição com Reichardt (Cf. Wackenroder, HKA II, p. 436). Cabe lembrar ainda que Wackenroder estudou música também com Fasch e Zelter: "Und ziehe mich still in das Land der Musik, als in das Land des Glaubens, zurück: Zu den pietistischen Grundlagen der Musikanschauung W. H. Wackenroders." (Cf. Tadday, 1999, p. 106).

5 Joseph Berglinger; Eine Studie zu Wackenroders Musiker-Dichtung, 1969.
} 
outra passagem - isolada do seu contexto original - para sustentar as suas hipóteses, confundindo, no mais das vezes, autor e personagem e sem levar em conta o contexto literário mais amplo do qual essas citações fazem parte. Desse modo, podemos perguntar: até que ponto as ideias expressas pelo mongenarrador ou pelo personagem de Joseph Berglinger realmente refletem as opiniões e os pontos de vista de Wackenroder e de Tieck enquanto teóricos? Sem querer solucionar definitivamente essa questão, examinaremos aqui alguns dos principais temas tratados nos dois livros publicados por Wackenroder e Tieck através de uma dupla perspectiva: levando em consideração, sempre que possível, as questões estéticas abordadas na correspondência de ambos dos anos de 1792/1793 e, além disso, procurando ter sempre em vista a dimensão literária em que os problemas filosóficos abordados estão inseridos.

Um primeiro aspecto a ser considerado é a figura do monge-narrador - que estará presente em ambos os livros - e aparece já no prefácio das Herzensergießungen. A escolha desse monge amante da arte como narrador, além de dar unidade à obra como um todo, traz consigo consequências importantes para a maneira de se abordar as questões estéticas no livro. A principal consequência é, sem dúvida, a determinação de uma certa perspectiva a respeito da arte, que será marcada notadamente por sua proximidade com a religião.

Ao tomar a arte como algo sagrado, o narrador considera que o artista - o gênio - recebe seu talento como dádiva divina, e a inspiração é imprescindível para a criação da verdadeira obra de arte. Essa visão a respeito da arte irá determinar, ao mesmo tempo, a postura do público (que deve ser marcada pela devoção e recolhimento perante a obra de arte) - e também do crítico de arte (pois, uma vez que a linguagem das palavras é insuficiente para apreender o divino da arte, teremos como consequência que uma obra de arte só pode ser descrita através de uma outra obra de arte).

Escritos na solidão da vida monástica, os textos teriam nascido não de um esforço teórico ou sistemático, mas de um "ímpeto interior" do narrador, desejoso de expressar a divindade da arte. Por isso mesmo, ele irá combater tanto a concepção que considera a arte como mero prazer dos sentidos, como também 
a concepção racionalista daqueles teóricos que abordam a arte com um olhar "crítico e frio". As crônicas sobre as vidas de grandes pintores do Renascimento italiano (Rafael, Michelangelo, Leonardo) e do Renascimento alemão (Dürer), que ocupam quase toda a primeira parte do livro, adotam, em certos momentos, um tom similar ao de uma hagiologia. Se a arte possui origem divina, esses grandes mestres seriam os "santos" da arte [Kunstheiligen].

A temática do gênio ocupa aqui um lugar de destaque. No ensaio sobre a morte do pintor Francesco Francia, por exemplo, o monge narra de que maneira o mesmo alcançou uma posição elevada na arte apenas por sua aplicação incansável [unermüdeten Fleiß] (Wackenroder, HKA I, p. 61). No entanto, embora sua obra possua, no geral, uma elevada qualidade técnica, falta-lhe justamente o gênio. E é somente em sua velhice, ao contemplar pela primeira vez um quadro pintado por Rafael, que Francesco Francia se dá conta da imensa distância que os separa, e que a genialidade corporificada na pintura de Rafael é um dom divino, que não pode ser alcançada pelo mero estudo da arte. Essa questão é aprofundada no ensaio seguinte, intitulado "Der Schüler und Raphael” [O aprendiz e Rafael]. Narrado sob forma epistolar, o jovem aprendiz se dirige a Rafael perguntando o que deve fazer para, em alguma medida, tornar-se semelhante a ele, pois diferentemente do que ocorre com as obras de outros mestres, o jovem relata a impossibilidade de se imitar suas obras, havendo sempre uma distância incomensurável entre a cópia e o original.

Em resposta ao jovem aprendiz, Rafael limita-se a dizer que ele próprio não sabe explicar como executa suas obras:

[...] infelizmente eu não posso te dizer o que desejas saber de mim. Não porque seja um segredo que eu não queira revelar - pois eu gostaria de comunicá-lo, do fundo do coração, a ti e a todos - mas porque eu mesmo o desconheço. [...] Tu não irás acreditar em mim, e, contudo assim o é. Assim como ninguém pode explicar a razão pela qual possui uma voz rouca ou suave, tampouco eu poderia te dizer por que os quadros, em minhas mãos, tomam justamente essa forma e não uma outra. [...] Que eu tenha justamente essa maneira de pintar, e não outra [...] me parece fazer parte de minha natureza; eu não a obtive através do amargo suor, e não é algo que possa ser deliberadamente estudado. (Wackenroder, HKA I, p. 68-69) 
Embora não tenhamos nenhum subsídio documental ${ }^{6}$ que nos permita apontar uma influência direta de Kant, não podemos deixar de notar a semelhança entre a concepção exposta nesta carta fictícia de Rafael e alguns aspectos da concepção acerca do gênio exposta na Terceira Crítica. Ali, no § 46 , Kant define a arte como um produto do gênio. E o gênio, por sua vez, era definido em primeiro lugar como sendo um talento inato, isto é, um dom natural e que não pode ser aprendido por meio de nenhuma regra. Assim, suas obras são marcadas pela originalidade e pela sua exemplaridade, ou seja, embora não tenham surgido por imitação, elas "têm de servir a outros como padrão de medida ou regra de julgamento" (Kant, KdU, § 46 B 182). Segundo Kant:

O produto de um gênio (de acordo com o que nele é atribuível ao gênio e não ao possível aprendizado ou à escola) é um exemplo não para a imitação [...], mas para a sucessão por um outro gênio, que por este meio é despertado para o sentimento da sua própria originalidade (Kant, KdU, § 46 B 200).

Embora a obra do gênio possa servir como modelo - não para a mera imitação - mas para despertar o outro gênio para sua própria originalidade, Kant afirma que o próprio gênio "não pode descrever ou indicar cientificamente como realiza seu produto":

[...] o próprio autor de um produto, que ele deve a seu gênio, não sabe como para isso as ideias se encontram nele e tampouco tem em seu poder [...] comunicá-las a outros em tais prescrições que os põem em condição de produzir produtos homogêneos (Kant, KdU, $\S 46$ B 182).

Mais adiante, Kant afirma que por mais minuciosos que possam ser os preceitos da arte poética, "não se pode aprender a poetar" [dichten lernen]:

\footnotetext{
${ }^{6}$ Deve-se lembrar, no entanto, a possibilidade de que Wackenroder e Tieck conhecessem a filosofia kantiana ao menos em segunda mão, por intermédio de Reichardt. Este publicara em sua revista, já no ano de 1791, diversos excertos da Crítica do Juízo - com especial ênfase aos parágrafos dedicados à teoria kantiana no gênio (A esse respeito, ver J. F. Reichardt, Musikalisches Kunstmagazin, 1791, p. 87-89).
} 
Nenhum Homero ou Wieland pode indicar como as suas ideias imaginosas, e contudo ao mesmo tempo cheias de pensamento, surgem e se reúnem em sua cabeça, porque ele mesmo não o sabe e portanto também não pode ensinar a nenhum outro.

Analogamente ao que ocorre no caso da poesia, na narrativa de Wackenroder o pintor Rafael relata que, embora tenha aprendido até certo ponto por imitação, há algo inato em seu fazer artístico que não foi aprendido nem pode ser ensinado, que simplesmente escapa ao âmbito do estudo e do exercício. Também aqui podemos traçar um paralelo com relação a Kant quando ele afirma que a arte bela pressupõe também um lado mecânico, passível de ser captado e seguido segundo regras. Ele afirma inclusive que esse lado mecânico é uma "condição essencial da arte” (Kant, KdU, § 47, B 186). Mas embora o lado mecânico seja uma condição necessária, ele não é uma condição suficiente, pois o produto da bela arte depende também da originalidade do talento do artista genial.

Essa união entre genialidade artística e o estudo da arte é exemplificado pelo monge-narrador num outro ensaio, que trata da vida do pintor Leonardo Da Vinci. Através da biografia de Leonardo, ele mostra que a inspiração genial tem 56 que estar unida a um estudo aplicado e profundo dos fundamentos da arte.

Como podemos ver, toda a primeira parte dos Herzensergießungen dedica-se principalmente à arte da pintura, representada pelos mestres do Renascimento italiano e alemão, que constituiriam uma espécie de "época de ouro" da arte, pois, estes eram gênios originais (ao contrário das épocas posteriores, que pretenderam tornar-se grandes imitando a grandeza dos antigos mestres).

Porém, ao voltar seu olhar para sua própria época (na segunda parte do livro), a pintura sai de cena e dá espaço à arte dos sons. Pode-se perguntar, então, por que Wackenroder teria escolhido justamente a música como representante da época moderna? Tendo em vista a teoria da arte esboçada ao longo da primeira parte do livro, podemos aventar algumas hipóteses. Em primeiro lugar, devido à proximidade entre música e religião. Essa proximidade já havia sido mencionada, muito de passagem, no ensaio sobre Albrecht Dürer, 
quando o narrador citava um escrito de Martinho Lutero, em que ele afirmava que "depois da Teologia, dentre todas as ciências e artes do espírito humano, é a música que ocupa o primeiro lugar" (Wackenroder, HKA I, p. 92). Além disso, a música é a arte da interioridade por excelência. Diferentemente das artes plásticas - pintura ou escultura - que expõem seus objetos visualmente no espaço, as obras musicais desdobram-se sucessivamente no tempo. A música é, portanto, uma arte progressiva e sentimental, no sentido schilleriano do termo. ${ }^{7}$ Com efeito, se os antigos (ingênuos) se caracterizavam pela arte da limitação [Begrenzung], os modernos (sentimentais) se caracterizam pela arte do infinito [Kunst des Unendlichen]:

A grande vantagem que as artes plásticas da Antiguidade afirmam sobre os tempos modernos e, acima de tudo, a relação desigual de valor em que estão a poesia e as artes plásticas modernas em face desses dois gêneros na Antiguidade explicam-se justamente pela força do artista antigo residir na limitação (e o que foi dito aqui do poeta pode, sob as restrições que se impõem por si, ser estendido ao artista em geral). Uma obra para o olho só encontra sua perfeição [Vollkommenheit] na limitação; uma obra para a imaginação [Einbildungskraft] pode alcançá-la também pelo ilimitado [Unbegrenzt]. [...] Em obras modernas isso é diferente, e se aqui os poetas antigos também vencem [...] naquilo que se pode expor sensivelmente e é corpóreo [körperlich], o moderno, por sua vez, pode deixá-los para trás na riqueza da matéria, naquilo que não pode se expor [undarstellbar] e é inefável [unaussprechlich], em suma, naquilo que nas obras de arte se chama espírito [Geist]. (Schiller, 1991, p. 63)

A partir dessas observações de Schiller resulta evidente que aquilo que ele afirma acerca da poesia vale também para a música. Pois a música não é justamente a arte que deixa para trás tudo o que é corpóreo e consegue expor o inefável? Com efeito, a afinidade especial entre a música e o gênero sentimental é

\footnotetext{
${ }^{7}$ As reflexões de Schiller sobre a poesia ingênua e sentimental [naive und sentimentalische Dichtung] foram publicados pela primeira vez na revista Die Horen entre 1795-1796 e é bastante provável que Wackenroder e Tieck tenham tomado conhecimento das mesmas.
} 
posta em relevo pelo próprio Schiller ao tratar de Klopstock, a quem denomina um "poeta musical” [musikalischen Dichter] e esclarece:

Digo musical para lembrar aqui a dupla afinidade da poesia, com a arte dos sons [Tonkunst] e com as artes plásticas [bildenden Kunst]. Ou seja, conforme imite um objeto determinado [bestimmten Gegenstand], como o fazem as artes plásticas, ou conforme produza apenas um estado da mente [Zustand des Gemüts], como a arte do som, sem ter para isso necessidade de um objeto determinado, a poesia pode ser chamada de plasmadora (plástica) ou de musical (Schiller, 1991[2002, p. 55], p. 75).

Assim, podemos perceber que não é por acaso que o artista moderno, na segunda parte do livro, será representado não mais por um pintor, mas sim, por um “artista dos sons” [Tonkünstler], isto é, por um compositor. Dessa forma, a partir do ensaio "Das merkwürdige musikalische Leben des Tonkünstlers Joseph Berglinger“ [A curiosa/singular vida musical do compositor Joseph Berglinger] há uma quebra na estrutura do livro, e o narrador abandona a perspectiva do historiador da arte passando a narrar a vida do amigo falecido a partir da lembrança dos seus relatos. A história de Berglinger é dividida pelo narrador em duas partes principais: na primeira, é narrada a infância de Berglinger, suas relações familiares e sociais, seu conflito interior e sua vocação para a música, culminando com sua fuga para a Residência Episcopal, a fim de se dedicar inteiramente à música. A segunda parte trata da inadequação do artista às exigências da sociedade da corte, do retorno à casa paterna e, por fim, da composição de sua última obra e da morte prematura de Berglinger.

Nascido numa pequena cidade no sul da Alemanha, Berglinger foi criado apenas pelo pai, um médico já idoso, cujo maior desejo era que o filho se dedicasse também a essa profissão. ${ }^{8}$ Desde muito cedo fica clara a inadequação de Berglinger à sua família - inadequação esta que, mais tarde, irá se estender à

\footnotetext{
${ }^{8}$ Muitos comentadores identificaram na história de Berglinger fortes traços autobiográficos de Wackenroder. No entanto, não iremos nos deter neste aspecto, uma vez que os possíveis paralelos entre as vidas de Wackenroder e do personagem Joseph Berglinger nos parecem ser de pouca relevância para a compreensão do livro.
} 
sociedade como um todo. O único consolo do jovem Berglinger será encontrado na arte da música e no impulso irresistível de tornar-se compositor e dedicar sua vida inteiramente à arte. Na medida em que não se trata da "escolha" por uma profissão como outra qualquer, mas de uma verdadeira "vocação" para a arte, no sentido religioso do termo, podemos notar a retomada do tema do gênio inato, mas agora no âmbito da arte musical. Desde o início da narrativa, o tema da interioridade do personagem se faz presente, o que, de certa forma, já prefigura a tendência de Berglinger em relação à música.

O narrador acentua também a força da imaginação de Berglinger, que desde pequeno vivia voltado para o seu fantasiar interior e cuja "principal alegria, desde os seus primeiros anos, era a música" (Wackenroder HKA I p. 131). Uma experiência decisiva deu-se durante uma viagem à casa de um parente numa cidade vizinha, que era também a Residência Episcopal. Nessa cidade, o pequeno Berglinger teve contato com a música sacra executada nas igrejas. Pela primeira vez ele tinha a oportunidade de ouvir "os Oratórios sacros, cantilenas e coros com tímpanos e trompetes" (Wackenroder HKA I p. 132). Sua atitude diante dessa música era de devoção interior ${ }^{9}$ [innerer Andacht] e, ao ouvi-la "ele se ajoelhava humildemente" (Wackenroder HKA I p. 132). Através da música Berlinger conseguia se afastar do mundo prosaico e "seu interior [Inneres] era purificado [...] de todas as mesquinharias terrenas" (Wackenroder HKA I p. 132). Quando a música finalmente chegava ao fim e ele voltava da igreja, era como se a música tivesse purificado e enobrecido a sua alma. Mas não apenas a música de igreja tinha esse efeito arrebatador sobre sua alma. Também a música de concerto era ouvida por ele com a mesma devoção que a música sacra:

\footnotetext{
${ }^{9}$ Em seu artigo sobre Wackenroder e Moritz, H. J. Schrimpf observa que esse conceito de devoção à arte [Andacht zur Kunst], que é central nas Herzensergießungen, já estava presente num romance inacabado de Moritz, editado em 1794, intitulado Die neue Cecilia. Ali, Moritz salienta que "o sentido para o belo da natureza e da arte é, originariamente, um sentido religioso, e é com 'devoção religiosa' que Cecília adentra o "santuário da arte'". Mas Schrimpf nota ainda uma importante mudança de ênfase de Moritz para Wackenroder: para este, "a religiosidade está fundada no ânimo [Gemüt] do artista, e não mais, como em Moritz [...] na beleza corpórea das figuras. A alegria dos sentidos pagãantiga é substituída pela interioridade cristã". (Cf. Schrimpf, 1964. p. 403-404)
} 
Quando Joseph estava em um grande concerto, ele se sentava num cantinho, sem nem olhar para o magnífico grupo de ouvintes, e ouvia com a mesma devoção [Andacht], como se ele estivesse na igreja [als er in die Kirche wäre], - igualmente quieto e imóvel, com os olhos fixos no chão. (Wackenroder HKA I p. 133)

A atitude ideal do espectador diante da obra de arte musical é descrita aqui através do exemplo do jovem Berglinger. Aqui fica claro que a atitude de devoção [Andacht] e recolhimento do ouvinte diante da música é fundamental, não importando se se trata de música religiosa ou de música de concerto. A atitude de respeito quase religioso do ouvinte perante a obra de arte musical deve ser a mesma. Além disso, o narrador enfatiza o completo desprezo de Berglinger pela música enquanto acontecimento meramente social. ${ }^{10}$ Se Kant ainda admitia a chamada "música de mesa" [Tafelmusik], que não é feita para se ouvir com atenção, mas para "preencher" o vazio e favorecer os convidados a uma alegre conversação ${ }^{11}$ entre si, Berglinger exige do ouvinte, diante de todo gênero musical, uma audição concentrada e atenta - muito semelhante àquela fruição verdadeiramente estética que, décadas mais tarde, seria definida por Hanslick como o escutar atento da sucessão de formas sonoras. Aliás, deve-se notar que apesar da defesa da música como expressão dos sentimentos, a atitude de Berglinger diante da obra de arte musical revela surpreendentes pontos de contato com a concepção estética de Eduard Hanslick. ${ }^{12}$ A atitude de Berglinger é a de um ouvinte completamente concentrado e ativo. Como o narrador salienta: "Nem o mínimo som Ihe escapava, e por causa dessa atenção [Aufmerksamkeit] tão intensa, ele ficava, ao final, totalmente cansado [ermüdet] e sem forças" (Wackenroder, HKA I, p. 133). Essa característica peculiar da fruição de uma obra

\footnotetext{
${ }^{10}$ Neste aspecto, a atitude de Berglinger já antecipa a do Kapellmeister Kreisler. Embora o personagem criado por Hoffmann não seja tão impregnado desse sentido de religiosidade característico de Berlinger, pode-se afirmar que ambos atribuem o mesmo valor elevado à arte musical. 11

Essa passagem encontra-se no $\S 44$ da Crítica do Juízo de Kant: “Artes agradáveis são aquelas que têm em vista simplesmente o gozo. [...] A isto pertence também [...] a música de mesa: uma coisa singular, que deve entreter, somente como um rumor agradável, a disposição dos ânimos à alegria e, sem que alguém conceda à sua composição a mínima atenção, favorece a livre conversação entre um vizinho e outro" (Cf. KANT, KdU, § 44, B 178). 12

Hanslick afirma que as obras musicais exigem do ouvinte "um acompanhamento incansável, na mais intensa atenção” (Cf. Hanslick, 1994 [1973, p. 78-79], p. 83).
} 
musical é mencionada também em duas cartas do próprio Wackenroder. Numa delas, datada de 27.11.1792, e endereçada a Tieck, ele afirma:

Ontem, como de costume, estive com Bernhardi no concerto das quartas-feiras. Como eu estou habitualmente muito atento [ao concerto], fica especialmente evidente para mim o quanto a música sempre me deixa cansado [müde]. (Wackenroder, HKA II, p. 91)

No entanto, a referência mais significativa de Wackenroder a esse respeito está numa carta enviada a Tieck em 05.05.1792:

\begin{abstract}
Quando vou a um concerto, penso que eu fruo a música sempre de duas maneiras. Somente uma maneira de fruição [Genuß] é a verdadeira [wahre]: ela consiste na mais atenta observação dos sons e seu avanço; na completa entrega da alma, nessa correnteza avassaladora de sentimentos; no distanciamento e afastamento de todo pensamento importuno e de toda impressão sensível que the seja estranha. Esse ávido sorver dos sons está ligado a um certo esforço [Anstrengung], que não se consegue aguentar por muito tempo. Justamente por causa disso é que eu acredito poder afirmar que só se consegue ouvir participativamente uma música durante uma hora, no máximo. Por isso, os concertos, óperas e operetas ultrapassam os limites da natureza. (Wackenroder, HKA II, p. 29)
\end{abstract}

Além do aspecto da recepção da obra de arte musical por parte do ouvinte, também a valorização da música instrumental, e em especial das sinfonias (Wackenroder, HKA I, p. 13), já é apontada no ensaio sobre Berglinger. Essa valorização está ligada à concepção da música como linguagem dos sentimentos (Wackenroder, HKA I, p. 133-134). Mas além disso, está ligada às qualidades de obscuridade e mistério, características da música instrumental. Diferentemente dos teóricos racionalistas, que consideravam tal obscuridade como um dos principais defeitos da música instrumental, para o narrador das Herzensergießungen, esse é "um dom maravilhoso da música”, a qual "possui um efeito ainda mais poderoso sobre nós, colocando em agitação todas as forças de nosso ser, quanto mais obscura e misteriosa [dunkler und geheimnisvoller] for a sua linguagem" (Wackenroder, HKA I, p. 134). 
O retorno de Berglinger à casa paterna, seu consequente retorno ao mundo prosaico e o afastamento do mundo da música seria comparável, de certa forma, à expulsão do homem do Paraíso. Após experienciar esse mundo ideal proporcionado pela música, torna-se ainda mais doloroso para Berglinger retornar a um ambiente ao qual ele sente não pertencer, e no qual está impedido de realizar suas aspirações mais profundas. Seu conflito interior entre arte e vida comum vai, aos poucos, tomando proporções insustentáveis. A dificuldade de Berglinger em se adaptar às preocupações mesquinhas do cotidiano pode ser vista como um reflexo - ou uma consequência - do sentimento de inadequação do artista perante o mundo prosaico. Aos poucos, sua vocação foi ficando mais evidente para ele: uma voz interior [innere Stimme] Ihe dizia incessantemente que ele havia nascido com uma finalidade mais elevada e nobre. Pouco a pouco, Berglinger se convenceu "de que tinha sido posto no mundo por Deus [...] a fim de que se tornasse um excelente artista na música" (Wackenroder, HKA I, p. 136). Nessa mesma época, Berglinger escreveu diversos poemas, os quais "ele musicou, sem conhecer as regras, em sua maneira pueril e repleta de sentimento" [recusa às poéticas prescritivas/expressão dos sentimentos do compositor através de sua obra] (p. 136). Após muito hesitar, Berglinger resolve abandonar a casa paterna e fugir para a cidade da Residência Episcopal, a fim de poder aprender a arte da música desde os seus fundamentos. Esse tema da fuga e da viagem é bastante comum na literatura romântica. A primeira frase do Werther, por exemplo, é significativa nesse sentido: "Sinto-me feliz por ter partido!" (Goethe, 1999 [1978, p. 7], p. 11). Elmar Hertrich nota que essa temática está relacionada à tentativa de fuga do herói romântico "do mundo limitado da burguesia, que não tem lugar para eles", e que esse herói está "sempre em busca de um mundo mais elevado, em que possa encontrar a sua realização" (Hertrich, 1969, p. 51).

A segunda parte do ensaio começa muitos anos após a fuga de Berglinger da casa paterna. Ele se tornou Kapellmeister na Residência Episcopal e vive agora rodeado por um grande esplendor. Mas o esplendor do mundo exterior em que vive só serve para acentuar ainda mais sua miséria interior. É com amargura que ele constata que a realização dos seus sonhos de infância, de tornar-se um artista 
e dedicar-se completamente à música, não o conduziu à felicidade desejada. Esse estado de ânimo é contado pelo próprio Berglinger, por meio de uma carta enviada ao narrador. Quanto à sua estrutura, podemos dividir a carta em quatro partes, nas quais ele aborda respectivamente sua relação com a música, com o público, com a sociedade de corte e com os demais músicos. A primeira parte da carta, que trata de sua relação com a música, gira em torno de sua recusa à "gramática da arte" [Kunstgrammatik],, isto é, às suas regras mecânicas, em favor da expressão imediata dos sentimentos através de suas obras. A esse respeito, é possível traçar novamente um paralelo entre Berglinger e Werther. $\mathrm{Na}$ carta de 26 de maio de 1771, Werther escreve:

Isso fortaleceu minha resolução de, doravante, ater-me exclusivamente à natureza. Só ela é infinitamente rica; só ela forma [bildet] o grande artista. Pode-se dizer muitas coisas em favor das regras, mais ou menos o que se pode dizer em favor da sociedade burguesa. Um homem que se forma de acordo com as regras jamais produzirá algo de mau-gosto ou ruim [...]; mas em compensação [...] toda regra destrói o verdadeiro sentimento da natureza e a verdadeira expressão do mesmo. (Goethe 1999 [1978, p. 19], p. 11)

Tanto no caso de Werther ${ }^{14}$ como no de Berglinger, não é apenas a recusa às regras que está em jogo, mas também a adequação a uma sociedade vista por eles como artificial, em que o parecer se sobrepõe ao ser, ou seja, em que as aparências contam mais do que os sentimentos genuínos. Na segunda parte da carta, Berglinger narra sua relação com o público:

${ }^{13}$ Segundo a definição de Forkel, a gramática musical [musikalische Grammatik] contém as regras [Vorschriften] para a conexão dos sons e acordes isolados [para a formação] das frases [Sätzen] e compreende os aspectos melódicos, harmônicos e rítmicos da música (Cf. Forkel, 1788, p. 21, 35-36).

14

$\mathrm{Na}$ carta de 24.12.1771, Werther escreve: “E a miséria resplandecente [glänzende Elend], o tédio [Langeweile] que reina entre a gente estúpida que se vê por aqui! E a mania de posicão social: espiam-se mutuamente apenas para encontrar uma oportunidade de passar a perna um no outro". Na carta de 08.01.1772, lemos ainda: "Que gente é essa, criaturas cujas almas são absorvidas pelas formalidades [Zeremoniell]; cujos interesses e esforços, durante anos inteiros, estão exclusivamente voltados em tentar conseguir a cadeira mais próxima da cabeceira da mesa de recepção! [...] Tolos, não vêem que o lugar nada significa, e que aquele que ocupa o primeiro posto nem sempre desempenha o papel mais importante!" (Goethe, 1999 [1978, p. 62-64], p. 72-73). 
Como eu pude imaginar que esses ouvintes orgulhosamente vestidos em ouro e seda reunir-se-iam para fruir uma obra de arte, para aquecer seus corações, para oferecer seus sentimentos ao artista! Se mesmo na majestosa catedral, nas festividades mais sagradas, quando tudo que existe de mais belo e grandioso na arte e na religião penetra com força sobre eles, [os corações] desses ouvintes não são aquecidos, por que isso iria acontecer na sala de concertos? - O sentimento e o senso para a arte saíram de moda e se tornaram vulgares; demonstrar seus sentimentos [ao contemplar] uma obra de arte seria tão estranho e ridículo como querer falar [...] utilizando versos e rimas, enquanto todos utilizam a prosa racional e compreensível para se fazer entender. É para essas almas que eu trabalho! [...] Esse é o alto destino, para o qual eu acreditava ter nascido! (Wackenroder, HKA I, p. 140).

Seu único consolo é imaginar que, mesmo muito tempo após a sua morte, alguém que possua uma tal simpatia com sua alma, consiga sentir, através de suas melodias, exatamente o que ele sentiu ao escrevê-las. Esse conceito de simpatia, que possui um papel central neste trecho, aparece também nas cartas de Wackenroder e Tieck, e está intimamente ligado ao ideal de expressão dos sentimentos através da arte, típicos da Empfindsamkeit:

Tudo o que nos agrada nas belas-artes, só pode agradar na medida em que cada artista toca aqueles sons que ressoam de maneira clara e pura em nossa alma [...], é só dessa maneira que o poeta pode nos comover, pois a comoção nada mais é do que a simpatia com a pessoa que nos comove $[\ldots . .$. .

Mas na sociedade de corte em que vive, Berglinger perdeu completamente as esperanças de encontrar um ouvinte simpático aos seus sentimentos: é em vão que ele tenta comover seus ouvintes. O fracasso de Berglinger como compositor não se deve ao seu suposto diletantismo, como acreditam alguns comentadores pois um diletante dificilmente alcançaria a posição de Kapellmeister da corte. As causas de seu fracasso devem ser buscadas, antes, no descompasso entre a sensibilidade romântica de Berglinger enquanto compositor - que deseja expressar seus sentimentos e a sua subjetividade através de suas obras - e o público cortesão para o qual ele escreve. O conflito de Berglinger reflete o

${ }^{15}$ Carta de Tieck a Wackenroder (29.05.1792). [In: Wackenroder, HKA II, p. 43] 
surgimento da figura do músico criador autônomo em oposição ao músico empregado da corte.

Essa subordinação da arte às vontades e aos caprichos da corte é algo insuportável para Berglinger. Pior ainda é a constatação de que os demais músicos da corte estão perfeitamente adaptados ao seu papel social, que consiste em entreter os ouvintes através da música. Esse conflito entre o artista genial e a sociedade, exposto através da figura de Berglinger, será também uma das principais marcas do personagem do Kapellmeister Kreisler, de E. T. A. Hoffmann - que irá retomar esse tema da inadequação do artista não mais no contexto da sociedade de corte, mas sim, no da sociedade burguesa. Da mesma forma, o tema da música como mero passatempo e prazer dos sentidos, que será abordado também por Hoffmann em alguns textos da Kreisleriana, já se faz presente nas Herzensergießungen:

Quão estranha e singular é a arte! Será que é só para mim que ela possui essa força tão misteriosa, enquanto para as outras pessoas ela é apenas divertimento dos sentidos e um agradável passatempo? O que ela é de fato, se para todas as pessoas a arte é um Nada, e somente para mim ela é Algo? Não é a mais infeliz das ideias fazer dessa arte a sua ocupação principal [...], dessa arte que na vida real terrena não desempenha nenhum papel diferente do que o jogo de cartas ou outro passatempo qualquer? (Wackenroder, HKA I, p. 142).

Quando uma das composições de Berglinger finalmente parece ter obtido o efeito que ele sempre desejara, tocando o coração de seus ouvintes, ele recebe a notícia de que seu pai está muito doente e que suas irmãs estão vivendo em situação miserável. Ele retorna à sua cidade natal, mas seu pai falece logo em seguida. Mesmo profundamente abalado pela morte do pai, Joseph deve retornar à Residência Episcopal para retomar suas atividades como compositor da corte. Como a Páscoa se aproxima, Berglinger deve compor uma nova música para ser usada na cerimônia da Sexta-feira da Paixão. Com lágrimas nos olhos, agitado por seus sentimentos e tomado por uma maravilhosa inspiração, ele compôs uma Paixão que, nas palavras do narrador: "com suas melodias penetrantes, contendo todas as dores do sofrimento, permanecerá eternamente 
como uma obra-prima" (Wackenroder, HKA I p. 142). Mas os esforços empregados na composição e execução de sua música foram demais para Berglinger, que adoece e morre pouco tempo depois.

\section{Os escritos musicais de Berglinger}

As Phantasien über die Kunst (1799) foram editadas e publicadas por Tieck pouco após a morte de Wackenroder. No "Prefácio", Tieck escreve que Wackenroder tinha uma especial preferência pelos ensaios sobre música e ele sempre desejou vê-los editados (Wackenroder, HKA I p. 142). Por se tratar de uma espécie de continuação do livro anterior, a estrutura básica continua a mesma: um conjunto de ensaios divididos em duas partes principais, sendo a primeira delas dedicada à pintura ou à arte de maneira geral, e a segunda parte, dedicada apenas à música, reúne os escritos do personagem Joseph Berglinger. Embora a figura do monge-narrador reapareça aqui, cabe notar que seu papel é bastante reduzido, se comparado ao livro anterior; especialmente na segunda parte, na qual, ao invés de narrar diretamente os acontecimentos, o monge 66 apenas assume o papel de editor ${ }^{16}$ dos ensaios e cartas que teriam sido escritos pelo próprio Berglinger, principalmente durante seus anos de aprendizado na Residência Episcopal.

Nos textos da primeira parte, reencontramos alguns dos temas principais que já haviam aparecido nas Herzensergießungen, como o papel da inspiração na arte, a conexão íntima entre arte e religião e a "divindade da arte" [Göttlichkeit der Kunst], considerada como o produto mais sublime do espírito humano. A tese da impossibilidade da descrição de uma obra de arte através da linguagem das palavras - que denota a influência das teorias de K. P. Moritz - é retomada no ensaio intitulado "Die Farben" [As Cores]. Ali, o narrador considera quase

\footnotetext{
${ }^{16}$ Novamente é possível, a esse respeito, fazer um paralelo com o Werther, no qual também encontramos a figura do editor que apenas organiza as cartas do amigo falecido. O significado dessa estratégia e de outras que presidem o gênero do romance na segunda metade do século XVIII é amplamente investigado por Raquel de Almeida Prado e por Franklin de Matos. (Ver R. A. Prado, 1997, p. 38ss; e também F. Matos, 2001, p. 223ss)
} 
impossível a tarefa de se descrever uma pintura, pois “as palavras permanecem mortas e [...] não explicam nada". É somente com uma descrição "genuinamente poética" que a linguagem das palavras consegue "suscitar um novo encanto" (Wackenroder, HKA I, p. 192).

É nesse mesmo ensaio que a arte musical começa a assumir um papel de maior relevância perante as demais artes. Tal como ocorre com as artes figurativas, também a música não pode ser descrita por meio de palavras. Novamente aqui, podemos perceber a influência de Moritz, para o qual a música estava para além dos limites da linguagem e conseguiria expressar o inefável, ou seja, aquilo "que as palavras não conseguem expressar" (Moritz, 1786, p. 71). Assim como Moritz, o monge-narrador considera a música como "um órgão mais fino que a linguagem":

A música é o último sopro dos espíritos, o elemento mais delicado, do qual os mais ocultos sonhos da alma tiram seu alimento [...], ela é um órgão mais fino que a linguagem, talvez mais delicado que seus pensamentos, o espírito não pode mais usá-la como meio, como instrumento, mas ela é a coisa mesma [die Sache selbst], por isso ela vive e oscila em seus próprios círculos mágicos. (Wackenroder, HKA I, p. 191-192)

O tema da autonomia da música - tratada como "a coisa mesma", e não como meio ou instrumento para um fim externo a ela - bem como a tese da música como uma linguagem menos grosseira que a linguagem das palavras, serão desenvolvidos com maior pormenor na segunda parte do livro, que reúne, como já mencionei, os ensaios sobre música que teriam sido escritos pelo próprio Berglinger.

No ensaio "Die Wunder der Tonkunst" [As Maravilhas/Milagres da Arte Musical], Berglinger descreve a música como sendo a mais maravilhosa das belasartes, pois somente ela "descreve sentimentos humanos de maneira sobrehumana e nos mostra todos os movimentos de nossa alma de forma incorpórea", utilizando uma língua "que não conhecemos na vida cotidiana, uma língua que aprendemos, não sabemos nem onde nem como, a única que gostaríamos de 
considerar como a linguagem dos anjos" (Wackenroder, HKA I, p. 207). É graças a essa linguagem obscura e intraduzível que a música obtém seus maiores efeitos. Ela não se dirige à razão, não deseja provar teses através de argumentos, mas penetra diretamente no coração e na alma de quem a ouve. De maneira mais poderosa do que as leis, a razão e a filosofia, a música fala diretamente ao coração (Wackenroder, HKA I, p. 230), através de uma força indescritível, que permanece inalcançável para a linguagem das palavras. Embora Berglinger reconheça que os fundamentos da música repousam nas leis matemáticas da acústica, ele defende que não é graças a esse elemento racional que a música consegue suscitar efeitos maravilhosos no coração de seus ouvintes. Para ele, existe uma obscura e misteriosa simpatia "entre as proporções matemáticas do som e cada uma das fibras do coração humano". Graças a essa simpatia indescritível, a música transformou-se "num mecanismo rico e dócil, adequado à representação dos sentimentos humanos" (Wackenroder, HKA I, p. 217).

Além dessa simpatia misteriosa entre o elemento material da música (isto é, o som), e os sentimentos humanos, Berglinger defende que há também um mecanismo de simpatia entre os sentimentos do artista e do ouvinte e que, em última instância, é válido não apenas para a música, mas para todas as artes de modo geral. De acordo com essa teoria, um sentimento só pode ser compreendido pelo sentimento, e "uma obra de arte só pode ser integralmente compreendida pelo mesmo sentimento que a produziu" (Wackenroder, HKA I, p. 219). Daí também a exigência de que o artista fale a partir de seu coração, pois somente se o próprio artista estiver comovido é que ele conseguirá comover seus ouvintes. Daí a crítica àqueles que apenas pensam ao invés de sentir:" "Quem quiser descobrir, com a varinha mágica da razão inquiridora, aquilo que só intimamente se pode sentir, descobrirá apenas pensamentos sobre o sentimento, mas nunca o próprio sentimento" (Wackenroder, HKA I, p. 218). E ainda:

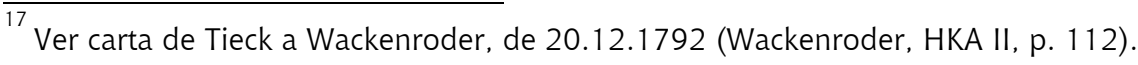


Que pretendem os racionalistas [...] desconfiados, que exigem a explicação por palavras de cada uma das centenas e centenas de obras musicais e não conseguem entender que nem todas têm um significado específico, como acontece na pintura? Pretenderão eles aferir a linguagem mais rica pela mais pobre e reduzi-la a palavras? Será que eles encheram o coração vazio apenas com descrições de sentimentos? (Wackenroder, HKA I, p. 219).

É no ensaio intitulado "Symphonien" [Sinfonias] que todos esses aspectos encontram uma espécie de síntese, cujas consequências seriam de grande importância para a estética musical posterior. A música, que é tida por Berglinger como "a mais obscura [dunkleste] de todas as artes", é considerada aqui como "o mistério último da fé, a mística, a religião totalmente revelada" (Wackenroder HKA I, p. 241). Essa valorização da obscuridade da música estava ligada à tese que considerava a música como uma linguagem dos sentimentos. Mas a tese mais radical, sem dúvida, é a que propõe a radical separação entre a música vocal e a música instrumental. Se tradicionalmente a música vocal era vista como superior, pois com o auxílio da poesia, ela conseguiria chegar a um grau de determinação que a música instrumental por si jamais conseguiria alcançar, a partir daqui teremos a inversão total desse ponto de vista: Berglinger defende que a música não deve ser considerada como um mero complemento da poesia, mas deve ser fruída por si só, em sua plena autonomia:

A música instrumental deveria, talvez, mover-se na sua própria força, respirar no seu elemento característico, sem qualquer acompanhamento instrumental; tal como a música instrumental segue o seu próprio caminho e não se interessa por nenhum texto, por nenhuma poesia subjacente, poetando para si própria e comentando-se a si mesma poeticamente. Ambas as formas [música vocal e música instrumental] podem existir independentemente puras e separadas. (Wackenroder, HKA I p. 242)

A defesa da música instrumental em sua autonomia só foi possível com a superação do princípio de imitação da natureza. No caso da arte dos sons, isso aparecia com clareza no ensaio “Die Töne” [Os sons], no qual Berglinger afirmava claramente que a música, já por meio de sua matéria-prima, não é uma arte 
imitativa [sie ahmt nicht nach], e que ela constitui um mundo isolado [abgesonderte Welt] por si mesma (Wackenroder, HKA I, p. 236).

Berglinger considera a música vocal como uma arte condicionada [bedingte]. Por estar ligada a um poema, ela é, em última instância, “apenas uma declamação, um discurso elevado", ao passo que somente a música instrumental é verdadeiramente independente e autônoma, pois "fixa para si as suas leis". Através do seu jogo livre, ela "alcança o objetivo mais elevado", e com sua linguagem obscura, ela "exprime o que há de mais profundo e de mais maravilhoso" (Wackenroder, HKA I, p. 243).

A linguagem misteriosa dos sons não necessita representar nada de exterior, de modo que matéria e objeto, forma e conteúdo encontram-se unidos, mais do que em qualquer outra forma de arte, de maneira indissolúvel:

Estas sinfonias podem representar um drama tão variegado, tão complexo [...], como o poeta jamais pode nos dar; pois que revelam em linguagem enigmática o que há de mais enigmático, não dependem de quaisquer leis da verossimilhança, não precisam recorrer a quaisquer histórias ou caracteres e permanecem em seu mundo puramente poético. [...] A matéria instrínseca é, desde o princípio até o fim, o seu objeto; a própria finalidade está presente em cada momento e com ela começa e termina a obra de arte. (Wackenroder, HKA I, p. 244)

\section{Considerações Finais}

Através da leitura dos ensaios sobre o compositor Joseph Berglinger, percebe-se a ligação desse personagem com as tradições estéticas da Empfindsamkeit e do Sturm und Drang, especialmente no que diz respeito à valorização da expressão subjetiva do artista através da obra de arte, bem como sua crítica às poéticas normativas, à criação e ao julgamento da obra de arte a partir de regras. Mas ao mesmo tempo em que muitos temas presentes nos textos musicais desse personagem possuem sua origem em movimentos estéticos anteriores, é preciso salientar também que esses textos contêm inúmeras ideias e problemas novos, que seriam retomados e retrabalhados por outros autores, de 
modo que se poderia considerar o personagem Joseph Berglinger como uma espécie de "elo entre Empfindsamkeit e Romantismo". Na formulação de Elmar Hertrich, Berglinger "marca o ponto de virada no qual o subjetivismo tardio da Empfindsamkeit faz surgir a problemática da arte e do artista do Romantismo" (Hertrich, 1969, p. 222). De especial interesse para o desenvolvimento de uma estética musical romântica foram, em primeiro lugar, o reconhecimento da obscuridade da música como índice de uma riqueza de significados que ultrapassa o âmbito limitado da linguagem das palavras. Em segundo lugar, a música deixa de ser vista como um passatempo agradável, mera fonte de deleite, e passa a ser vista como forma de acesso ao divino, "o mistério último da fé", "a Religião totalmente revelada" (Wackenroder, HKA I, p. 241). Essas formulações abrem caminho para a concepção romântica, ${ }^{18}$ em que a música se torna não somente a mais elevada dentre as belas-artes, mas também o lugar privilegiado de experiência do Absoluto.

\footnotetext{
${ }^{18}$ Waizbort observa, com razão, que "a religião da arte romântica foi uma emancipação da arte, que deixou de servir a qualquer função que lhe fosse exterior, deixou de ser música funcional. Isso se concretizou sobretudo na música instrumental; liberta de vínculo com a língua, apenas ela constitui-se como música plena e pura" (Waizbort, 2008, p. 186).
} 


\section{Referências}

ALEWYN, R. Wackenroders Anteil. Germanic Review, v. 19, n. 1, p. 48-58, 1944.

BEHLER, E. Wackenroder y la concepción musical del Primer Romanticismo. Anuário Filosófico, v. 29, p. 21-39, 1996.

FORKEL, J. N. Allgemeine Geschichte der Musik I. Leipzig: Schwickert, 1788.

GOETHE, J. W. Die Leiden des jungen Werther. München: DTV, 1978. p. 7. Trad. Bras. Os sofrimentos do jovem Werther. Trad. L. C. Lack. São Paulo: Nova Alexandria, 1999.

HANSLICK, E. Vom musikalisch-Schönen. Darmstadt: Wissenschaftliche Buchgesellschaft, 1973. Trad. Port. Do Belo Musical. Trad. A. Morão. Lisboa: Ed. 70, 1994.

HERTRICH, E. Joseph Berglinger: eine Studie zu Wackenroders Musiker-Dichtung. Berlin: Walter de Gruyter, 1969.

HUBeRT, U. Karl Philipp Moritz und die Anfänge der Romantik. Frankfurt a.M.: Athenäum, 1971.

KANT, I. Kritik der Urteilskraft. Hamburg: Felix Meiner, 2001. Trad. Port.: Crítica da Faculdade do Juízo. Trad. A. Marques e V. Rohden. Lisboa: Imprensa Nacional, 1998 (Abrev. KdU).

MATOS, F. O filósofo e o comediante: ensaios sobre literatura e filosofia na Ilustração. Belo Horizonte: Ed. UFMG, 2001

MORITZ, K. P. Andreas Hartknopf: eine Allegorie. Berlin: Unger, 1786.

PRADO, R. A. Perversão da retórica, retórica da perversão: moralidade e forma literária em 'As ligações perigosas' de Choderlos de Laclos. São Paulo: Ed. 34, 1997.

REICHARDT, J. F. Musikalisches Kunstmagazin. Berlin: Im Verlage des Verfassers, 1791. 2. Bd. (7. Stück).

SCHILLER, F. Über naive und sentimentalische Dichtung. Stuttgart: Reclam, 2002. Trad. Bras. Poesia ingênua e sentimental. Trad. M. Suzuki. São Paulo: Iluminuras, 1991.

SCHRIMPF, H.-J.; W. H. Wackenroder und K. Ph. Moritz: Ein Beitrag zur frühromantischen Selbstkritik. Zeitschrift für deutsche Philologie, Bd. 84, p. 385-409, 1964.

STRACK, F. Die 'göttliche' Kunst und ihre Sprache. Zum Kunst- und Religionsbegriff bei Wackenroder, Tieck und Novalis. In: BRINKMANN, R. (Hg.). Romantik in Deutschland. Stuttgart: Metzler, 1978. p. 369-391.

TADDAY, U. Und ziehe mich still in das Land der Musik, als in das Land des Glaubens, zurück: Zu den pietistischen Grundlagen der Musikanschauung W. H. Wackenroders. Archiv für Musikwissenschaft 56, Heft 2, p. 101-109, 1999. 
WACKENRODER, W. H. Sämtliche Werke und Briefe. Historisch-kritische Ausgabe in 2 Bde. Hg. S. Vietta; R. Littlejohns. Heidelberg: Carl Winter, 1991 (Abrev. HKA). Tradução parcial portuguesa: IRIARTE, R. (Org). Música e Literatura no Romantismo Alemão. Lisboa: Apaginastantas, 1987.

WAIZBORT, L. Chaves para ouvir Schumann (paralipomena à Kreisleriana - I). Novos Estudos Cebrap, v. 75, p. 185-210, 2008.

O presente artigo apresenta os resultados parciais da tese de doutorado intitulada " $\mathrm{A}$ linguagem do inefável: música e autonomia estética no Romantismo alemão", realizada na Universidade de São Paulo, sob orientação do Prof. Dr. Marco Aurélio Werle (com estágio na Universidade de Tübingen, supervisionado pelo Prof. Dr. Manfred Frank. Esta pesquisa teve o apoio financeiro da Capes, do CNPq e do DAAD.

Mário Videira: m_videira@yahoo.com

Artigo recebido e aprovado em 17/09/2010 